Forbes, L. H., Rybkowski, Z. K., and Tsao, C. Y. (2018). "The evolution of lean construction education (Part 2 of 2): At US-based companies," In: Proc. $26^{\text {th }}$ Annual Conference of the International. Group for Lean Construction (IGLC), González, V.A. (ed.), Chennai, India, pp. 1024-1034. DOI: doi.org/10.24928/2018/0463.Available at: www.iglc.net.

\title{
THE EVOLUTION OF LEAN CONSTRUCTION EDUCATION (PART 2 OF 2): AT US-BASED COMPANIES
}

\author{
Lincoln H. Forbes ${ }^{1}$, Zofia K. Rybkowski ${ }^{2}$, and Cynthia C.Y. Tsao ${ }^{3}$
}

\begin{abstract}
The benefits of lean projects such as reduced schedules and budgets are well documented; construction organizations accomplish lean project delivery through the practices of project teams, yet the backgrounds of many participants have relatively little involvement with lean methodology due to its relative newness. Many participants in the lean movement such as members of the Lean Construction Institute (LCI) attribute project success to the training that is typically conducted to create an awareness and capability among participants and align the team with the priorities of the project. A study of leading firms was undertaken to examine this linkage by reviewing how training is provided for project teams, including the work force. A cross-section of established construction firms, design firms, and consultants were surveyed to determine the best practices that are currently in use. These organizations are all members of LCI or the Associated General Contractors (AGC).

Many important lessons were learned, including: the successful approaches taken by AGC to provide industry training; the best practices of the companies surveyed; and future opportunities for improvement in lean training at the industry level. Notably, some of the approaches used in academia such as simulations, were used, but some companies were developing their own training, emphasizing leadership over tools.
\end{abstract}

\section{KEYWORDS}

Lean construction education, Lean Construction Institute, Associated General Contractors, CM-lean certificate, leadership.

\section{INTRODUCTION}

The purpose of this study was to review the evolution of Lean Construction education with US-based, Owner, Architect, Engineering, and Construction (OAEC) stakeholders. The following sections provide case study examples of lean educational initiatives

1 Adjunct Professor, East Carolina University, Greenville, NC, USA; and Lean Researcher, Harding Associates Inc., Miami, FL, USA, lhforbes@ gmail.com +1 305 546-6239.

2 Associate Professor, Department of Construction Science, Texas A\&M University, College Station, TX 77845-3137, USA, +1 979 845-4354, zrybkowski@ tamu.edu

3 Owner, Navilean, Brookline, MA 02445, USA, Phone +1 510/593-4884, research@ navilean.com 
offered within industry by LCI and AGC as well as strategies used by lean company champions and independent lean consultants.

The underperformance of the construction industry is well documented (Koskela 1992 and2000; Teicholz 2001; Eastman et al. 2008, and the McKinsey Global Institute 2017). In particular, most recently the McKinsey study identified a growth rate of $1 \%$ annually in the construction industry during a recent 20-year period of study compared with $2.8 \%$ for the total world economy and 3.6\% for manufacturing.

Lean construction emerged as a response to frustration with low construction productivity, errors, delays, cost overruns and safety. However, a survey from a 2003 report by McGraw Hill revealed that major challenges to implementing lean on a job site included: (1) lack of lean knowledge, (2) lack of sufficient support, (3) perception that lean is too complex, (4) employee resistance, and (5) lack of industry support (McGraw Hill 2003). Despite these challenges, the OAEC industry has steadily work on lean implementation, and a decade later, practitioners have noted that the benefits of lean implementation include improved safety, higher customer satisfaction, high quality construction, reduced schedules, reduced costs, greater profitability, and better risk management (McGraw Hill Construction 2013).

\section{METHODOLOGY}

A modified Delphi approach was utilized, drawing on the expertise of executives, lean champions and trainers from several OAEC organizations that are known for their leadership in lean construction projects. Fourteen (14) individuals were contacted (as subject matter experts) both by email and/or conference calls to identify the strategies used by OAEC stakeholder companies to impart lean practices to employees, To establish a common frame of reference, open-ended questions were asked about their organizations' mission/corporate philosophy, lean journey, their personal lean background, training approach, lean implementation tools, and how they address the barriers to lean implementation.

\section{OUTCOMES}

While the above questions did not apply equally to all respondents, summaries of their responses are included below, as appropriate.

\section{LEAN CONSTRUCTION INSTITUTE (LCI)}

The Lean Construction Institute (LCI) was founded by Greg Howell and Glenn Ballard in 1997 "as a way to develop and disseminate new knowledge regarding the management of work in projects" (LCI 2017a). LCI offers a variety of educational resources, including organizing the LCI Congress which rotates to different cities on an annual basis. LCI provides educational resources to 31 Communities of Practice throughout the US, and hosts Internet-accessible webinars, lean coffees, and happy hours. It publishes and distributes educational books and lean simulations, including the Make-a-Card-Game (that is, a variation of the Lego Airplane Game), the Parade of Trades (Tommelein et al. 1999), and Silent Squares (LCI 2017b). LCI also publishes the Lean Construction 
Journal (LCJ). Since 2003, LCJ articles have made peer-reviewed experimental results and case studies from academics and practitioners freely available (LCJ 2017).

According to Executive Director Dan Heinemeier, although LCI has chosen not to develop its own certification program, it partners with AGC, which offers a lean certification program. LCI's Education Programs Director Kristin Hill stated that the LCI approach to Lean Construction education is to enhance awareness through its annual LCI Congress and Design Forum events. Based on recommendations from LCI's Education Committee, a number of learning modules were rolled out locally (up to 5); they are faceto-face and very interactive. They include a number of simulations in the "Introduction to Lean" class, the Parade of Trades and the "Make a Card" Game. There is also a Big Room simulation and a Target Value Delivery (TVD) module that simulates interactions within a project team as they go through a project and seek to lower costs.

LCI's corporate membership includes approximately 35 to 40 owner member companies, including Proctor and Gamble, Intel, and Universal Health Systems (UHS). Four or five representatives sit on the LCI Board. LCI provides incentives to member companies such as a) having a complimentary "Introduction to lean" presentation, or b) Attendance of one (1) employee at the Annual Congress. Thus, owners have begun to wield some influence in the development of LCI's priorities - which is greatly desirable for increasing construction industry demand for the application of lean principles. According to Heinemeier, one measure of LCI's success is its expansion from fewer than 100 member companies in 2013 to over 200 in 2017, and growth from approximately 800 LCI Congress attendees in 2014 to over 1500 attendees in 2017. Almost two-thirds of Congress participants also attend lean training courses while there (Dan Heinemeier and Kristin Hill, Personal Communication, Nov. 7, 2017; Konchar and Mahshum 2017).

\section{ASSOCIATED GENERAL CONTRACTORS (AGC)}

Effective lean implementation requires collaboration by multiple project stakeholders who understand the principles, practices, and spirit of Lean Construction. Recognizing the enormity of the educational task vis-à-vis the OAEC stakeholder community, former AGC president Chuck Greco engaged Tariq Abdelhamid of Enovio Consulting from 2009 until 2013 under a research contract with Michigan State University to develop a standardized lean construction education program. Abdelhamid's initial four unitshave since expanded to comprise an interactive 50-minute Lean 101: Foundations of Lean Construction web-based introduction and a 35-hour in-seat modular educational program.

Approximately118 lean construction specialists throughout the US teach the seven units. The units are delivered in a bricks-and-mortar (versus on-line) setting. Although each instructor presents the material in a slightly different way, he or she aligns the course with specialized AGC textbooks and also administers the same simulations. For example, lean consultant Colin Milberg is one of the instructors who regularly delivers the course for the Boston-area AGC. While he sometimes presents the material as a weeklong block, he prefers to teach on Fridays with "off-weeks" in between. Typically, Milberg consolidates Units $1 \& 2$ and $3 \& 4$ into two separate full-days, whereas Units 5, 6 , and 7 are offered as "standalone" days. During Units $1 \& 2$, participants encounter the concepts of flow, variation and bottlenecks. In Units $3 \& 4$, they are introduced to pull 
planning and Last Planner ${ }^{\circledR}$. In the remaining units, Milberg introduces the principles of visual management, transparency, supply chain management, cross-docking, A3s, target value design, root cause analysis, the lean triangle, co-location, kanban, Choosing by Advantages (CBA; Suhr 1999), Plan-Do-Study-Act, etc. Participants play additional simulations including the 5S Numbers Game (Superteams 2016) and the Marshmallow Challenge (Wujec 2012) (Colin Milberg, Personal Communication, November 20, 2017).

After completing all seven modules, students can take a four-hour, 150-question multiple-choice test. Upon passing, they are awarded a certificate. According to AGC's Curriculum Development Director, Warren Kiesel, 600 people earned the credential between the program's inception in Oct2015, and Nov2017. At the 2017 LCI Congress, all 35-seated courses were completely sold out. It is clear to Kiesel that as soon as AGC offered the lean certificate credential, the program took off - "People want to take the course as fast as they can. "He also notes that construction activity in the US is back to pre-downturn levels but is being accomplished with $13 \%$ fewer workers in 2017 . He thinks this increased productivity may be related to an emphasis on BIM and prefabrication. Lean project adoption seems greatest among Owner organizations - such as hospitals - who have to live with the finished facilities. "Spec" builders seem less interested; they apply heavy price pressure in the acquisition of design and construction services. Their market may be less sensitive to the improved functionality and quality that lean projects typically offer (Warren Kiesel, Personal Communication, Nov.14, 2017).

\section{LEAN COMPANY CHAMPIONS}

\section{Example 1: General Contractor: J.E. Dunn}

Many companies like JE Dunn have developed their own lean champions to guide their organization's lean journeys. Rebecca Snelling joined JE Dunn in 2012 after working as a lean consultant with lean construction pioneers Hal Macomber and John Draper, bringing the company substantial savings on several projects. Snelling said the company decided to engage her on a permanent basis instead of a project-by-project basis. Five years later, Snelling has grown her lean division staff to 10 employees. She says JE Dunn is not using AGC training at this time since they offer their own tailored form of instruction.

Snelling said she typically introduces Lean to employees by facilitating the Lego ${ }^{\mathrm{TM}}$ Airplane Game, the Parade of Trades, and Silent Squares. On a typical project, every member of the project team, including trades, is provided with a one-day training class that focuses on lean thinking and the specific tools that a project will use. Separately from that, all employees (project and non-project) go through a one-day lean training that is focused on lean principles and tools that they can apply to their own work. With regard to support, Rebecca's team typically helps a project team with lean facilitation at project inception. Rather than teaching pull planning using the DPR blocks game or Villego ${ }^{\circledR}$ (Villego 2017)for example, Snelling demonstrates the process to a superintendent or project manager (PM) on an actual project in three ways: first, by facilitating a pull plan in front of a superintendent or PM; second, by co-facilitating a pull plan with the same superintendent or PM; and third, by observing the superintendent or PM administer a pull plan on his or her own. Snelling then provides feedback in a plus-delta format. 
The team has a variety of skills on tap; some are knowledgeable about IPD, and others about the Last Planner System (LPS). They are dispatched to different project locations; two members help to provide content on procedures for the company. The team comprises people of different backgrounds; some used to be project managers, or superintendents; while others have prior experience in manufacturing. Snelling has taught participants to teach lean to others. In Rebecca's words, "These people do not grow on trees." During hiring, she said she looks for rising stars who are both humble and curious.(Rebecca Snelling, Personal Communication, November 7, 2017).

\section{Example 2: General Contractor: DPR Construction}

DPR Construction has been active in shaping lean thought through the pioneering involvement of Dean Reed and his interaction with Stanford and UC Berkeley during Lean Construction's formative years. East Coast Leader of Lean and Project Executive, Chris Dierks, is a strong believer in workshops and focuses participants on what it means to have a lean mindset. Projects start with teaching and learning and Chris plans these activities to best match the dynamics of a project by varying the duration and agenda; a project with a smaller overall duration may need only one short workshop, while others may work best with multiple half-day or full day workshops. There is much emphasis on having team members getting to know each other. DPR's commitment to lean is evidenced by having these activities whether or not the owner asks for a project to be lean. The curriculum typically includes Silent Squares, the Airplane Game, and the DPR Pull Planning Exercise.

DPR stresses establishing Conditions of Satisfaction (CoS), and defining value; owners' representatives are almost always included, as are the key trade partners. The process is sometimes leveraged by having a knowledgeable trade partner lead portions of the training; different people are used to lead Gembawalks, present the Last Planner System, etc. while being active participants in projects. "Go and See" projects are considered to be important; special recognition is given to successful project teams and the company creates a platform to transfer knowledge to other project teams.

DPR's employee lean training involves simulations including the Lego ${ }^{\circledR}$ Airplane Game, Silent Squares, and the DPR Pull-Planning Game (Visionary Products 2008; LCI 2017b; King 2011; Tsao et al. 2014). Interestingly, although they encourage their employees to take the AGC lean course and occasionally teach local classes, DPR has departed from focusing on tools and has instead turned its attention to an emphasis on leadership, exposing its employees to a nine-week program called "Lean Leadership" where the largest focus is on building teams. Cory Hackler the "West Coast Leader of Lean" and Erika Byse guide 20 to 30 people at a time with two to three courses being offered simultaneously. Students are asked to build individual radar charts to plot personal strengths, as well as areas in which they can improve. They are then encouraged to find someone who scores highly in an area in which they feel they need to improve, in order to learn from that individual. The success of the program is borne out by the fact that 220 people are waiting to take the course. In post-course evaluations, $100 \%$ of the attendees have recommended the course to others. 
With regard to performance metrics, DPR is studying past projects to determine which ones are the most relevant. Hackler and Byse concur that DPR is intensifying its focus on the "respect for people" part of the definition of lean construction (Erika Byse, Chris Dierks, Cory Hackler, and Dean Reed, Personal Communication, Nov. 21, 2017).

\section{Example 3: General Contractor: Linbeck Group, LLC}

Linbeck Group based in Texas is one of the earliest general contractors to experiment with lean construction. According to Stewart Trapino, in 1968Leo Linbeck Jr. responded to a client's urgent request to reduce cost and schedule. He fortuitously uncovered many of the principles that now are associated with the IPD approach: early involvement, collaboration, openness concerning cost, target costing as a method (vs. value engineering), and a commitment to providing the best value (Stewart Trapino, Email Communication, January 4, 2018). Then in 1998, Leo Linbeck III formally introduced lean as a management system to the company, having met Greg Howell and Glenn Ballard while completing his MBA at Stanford. The Lean Construction Institute worked with Linbeck to implement the Last Planner ${ }^{\mathrm{TM}}$ System of Production Control (LPS) on a project for Rice University--a move which led to LPS being used on every Linbeck project until 2012. However, because of the perceived complexity of LPS, Linbeck's management struggled to convince its employees to fully implement it. It was at this time the company's management developed its "Lean Boards" system as a way to simplify LPS. The boards were inexpensive, could be packed up in a suitcase, and provided a platform to support pull planning, daily huddles, PPC tracking, and accountability.

In a 2014 company meeting, Paul Akers encouraged employees to read his book 2Second Lean (Akers 2014) and use their cell phones to create "before and after" videos recommending opportunities for improvement on site. The company hosts a spoof of the Academy Awards at their annual meeting and presents video winners with small "head" statues in lieu of the Oscar statuette. The videos are posted on the company website for others to see (https://www.linbeck.com/lean), and new employees are asked to watch the videos so work improvements can be adopted and standardized. Also, all employees are encouraged to complete the AGC Lean education program and demonstrate they have mastered Lean Boards, make and share at least one lean video, and teach one or more AGC lean units(Stewart Trapino, Personal Communication, January 4, 2018).

Project manager and company lean champions Sean Sachtelbenand David Noonan say lean is deeply embedded in the Linbeck culture. They put great emphasis on combatting the eight wastes of lean (the eighth defined as "unused employee genius") and Sachtelben and Noonan carrya list of the eight wastes on a pocket card as a constant strategic reminder. The two tools they use most often include: (1) pull planning, and (2) Lean board tracking. All Linbeck projects are pull-planned and involve posting a master (milestone) schedule, phase schedule, two week-lookahead plan, and weekly work plan. Lean board tracking charts are posted to a white board on casters instead of a job trailer wall so it is made readily available wherever workers are engaged at any point in time.

Sachtelben and Noonan said they stress to employees that lean is simple. For example, as project managers, they move the dumpster and locate portable toilets to areas that are convenient for their workers, reducing the waste of unnecessary movement. They store 
tools in easy-to-find gang boxes so “ $\$ 25 /$ hourworkers don't repeatedly waste20 minutes searching for equipment." Since many construction activities are repetitive, small continuous improvements lead to substantial savings. Sachtelben also said Linbeck has a number of project managers who rotate as lean champions. They travel to one another's site locations (i.e. Houston, Dallas, etc.), socialize and exchange "ideas that work".(Sean Sachtelben and David Noonan, Personal Communication, November 28, 2017).

\section{Example 4: Architecture firm Boulder Associates}

Several architects have begun experimenting with the application of lean construction methods to design thinking. According to Todd Henderson, a principal at Boulder Associates, Romano Nickerson, also a principal, began experimenting with applying the Last Planner ${ }^{\circledR}$ to design. Nickerson was an early advocate of lean who sought to remove waste from his own work. For Henderson, a turning point came when Nickerson shared a graph of staff working hours with his colleagues; three-quarters of the staff were accustomed to working on Saturdays and Sundays. Following the application of the Last Planner $^{\circledR}$, workflows steadied and staff found they were then able to spend weekends away from the office. The method spread laterally at a grass roots level via staff members assigned to multiple projects who then "mentored up" to other managers. Company directors recognized the positives in lean thinking and adopted the "Work Plan"Boulder's lean initiative. Despite the 2009 recession, and a downsizing of nearly onefourth of their staff, Boulder Associates doubled their profits.

Henderson explained that as an office, they have read and discussed Liker's The Toyota Way (2003) about six times. In truth, they are finding it difficult to sustain lean processes, and do observe themselves backsliding at times. As a design firm, Henderson admits they are discovering that Agile and Scrum, which are heavily practiced by the software design industry, may be a better fit for the "loopy" iterative process of architectural design than the Last Planner ${ }^{\circledR}$ System. The LPS seems better suited for the more linear processes used by general contractors, although there is some disagreement about this. (Todd Henderson, Personal Communication, November 11, 2017).

\section{LEAN CONSULTANTS}

Hal Macomber is an example of a lean construction pioneer who has offered a solid foundation for next-generation lean consultants, including the likes of Rebecca Snelling (now at JE Dunn), Colin Milberg (now founder of ASKM Associates), and Cynthia Tsao (now a lean coach, educator, and researcher at Consigli Construction Co, Inc.). Macomber has made critical contributions in the development of lean practices that have now become mainstream. They include Study Action Teams (SATs), as well as several ideas seminal to lean construction, including Reliable Promises as part of language action theory. He also co-authored with Greg Howell the "Five Big Ideas" for corporate pioneer Sutter Health in the early 2000s as they embarked on a major construction program and took a leap of faith with the then emerging lean methodology. The ideas were embodied in an Integrated Form of Agreement (IFOA) and ultimately in AGC's Consensus Docs. Hal's contributions also include the "Good 5 Why" process. Hespent time in Japan in the mid-1980s as part of a program with the Japan Union of Scientists and Engineers (JUSE) 
that exposed him to total quality and time-based management. Although he since consulted for various technical industries, Macomber ultimately chose to focus on construction, and the 2017 Macomber and Davey book, The Pocket Sensei, reflects the Japanese influence.

What is especially interesting about Macomber's recent work however, is that instead of being interested in lean tools, he is most concerned with kata-a practice involving personal reflection which leads to continuous improvement. Reflection means an individual observes what he or she is learning, and because of this, continuous improvement becomes automatic, almost involuntary. For example, if a kata-enlightened staff at Toyota spies a stray paperclip on the floor, he will pick it up without being told; if a diploma in an employee's office is misaligned, another employee will straighten it without asking. Macomber argues that few companies now claiming to be lean actually are because most are missing a type of automatic, "muscle-memory" form of continuous improvement which is key to a true organization-wide lean culture. If his observation is correct, kata may help resolve the difficulty expressed by several companies of maintaining lean within their organizations long-term. In fact, kata may serve as the interstitial glue that holds together the parts of the elephant we call lean (Hal Macomber, Personal Communication, November 22, 2017).

\section{OWNER ORGANIZATIONS}

James Pease is a Regional Manager with Sutter Healthcare in Northern California. Heleads a team of 7 Project Managers who manage approximately 100 projects valued at $\$ 350 \mathrm{M}$ in the greater Sacramento Area. Sutter's mission is to enhance the well-being of people in the communities served through a not-for-profit commitment to compassion and excellence in healthcare services. .

Sutter's lean journey started as a need to meet a California Senate Bill that required the replacement of most of their hospitals starting in the late 1990's. Having limited success with earlier projects, Sutter looked for new approaches to deliver an estimated \$7 billion program in the early 2000's and was led by its construction attorney Will Lichtig to seek guidance from Greg Howell and Glenn Ballard. Dave Pixley, the Director of Construction, embraced lean construction and saw significant success with the initial project implementations. Subsequently, all projects have been lean-based, including design and construction work. One provider, Herrero Builders, through Paulo Napolitano created a Lean training program for its partners and clients on an IPD project.

Building on these successes, Sutter appointed a director of Lean Integrated Project Delivery - Digby Christian. He leads a 5-day Lean and IPD training for all PMs and project controllers. Sutter has developed in-house resources for IPD best practices; Last Planner and Target Value Design concepts are usually taught through LCI meetings or conferences. Sutter also often hires consultants to get new project teams started.

The simulations used include the DPR Block Game, Parade of Trades, and Villego. One day per month is reserved for staff training although it is primarily process-driven.

Last Planner training and education are done at the start of projects - including the design and construction partners. Trade partners are also selected based on these abilities. The 
majority of the training is hands-on at the project level. Christian's training is held once for each Project Manager and a sequel to that program is being developed.

With regard to implementation barriers, projects tend towards chaos and it takes work to keep them organized. Overall, the dedication to lean from the internal construction administration structure has proven to be successful in creating a lean culture, and in engaging the services of providers who are highly capable... With this support from the administration, including Dig by Christian and TanosLampsas, James Pease believes it is unlikely that project team members - both internal and external will backslide to traditional behaviors. (James Pease - Personal Communication - February, 2018)

\section{CONCLUSION}

This paper describes LC teaching approaches in the OAEC community, including LCI, AGC, design firms, construction organizations, and training consultants; it complements Part 1 of the series that focuses on academia.

The results of this new study with lean construction leaders in the U.S. provide valuable lessons for the construction industry in improving lean deployment. The findings suggest that many OAEC stakeholders view a knowledge of lean as providing a competitive advantage, and are trying to deploy lean training as rapidly as possible. Interest in lean construction and IPD has accelerated in recent years with even greater interest in the training that is provided at LCI conferences. Construction professionals have been actively seeking the AGC's CM-Lean credential. The AGC program mirrors the simulation approach used in academia with foundational concepts such as visual management, transparency, supply chain management, and root-cause analysis.

Construction organizations have been adopting the model of internal "lean champions" as exemplified by DPR Construction, JE Dunn Construction, and Linbeck Construction. Lean deployment is far from uniform and is constantly evolving, from having structured training programs in some cases, to simply promoting waste reduction as an internal culture. While lean consulting firms offer training that contains many of the tools encountered in academic programs, companies such as DPR have begun to emphasize the role of leadership in the lean transformation. Design firms such as Boulder Associates have many successful lean projects to their credit. However, in the spirit of continuous improvement for design projects they are gravitating towards a more advantageous scrum/agile methodology. Owner organizations such as Sutter Healthcare attribute the success of their projects to their commitment to lean and active participation and leadership in deploying the lean methodology through their project teams.

Given the wide variety of approaches used by companies in training members of the project team, a number of questions arrive: How do individual methods stack up against a cost/benefit analysis? How should the training be adjusted to match the needs of a specific project? How does "just in time" training compare in effectiveness with routine training? It would be useful to develop an inventory of the tools/techniques used by industry practitioners as was done in Part 1of this two-part paper. 


\section{REFERENCES}

Akers, P. A. (2014). 2-Second Lean: How to grow people and build a lean culture, $3^{\text {rd }}$ edition, <https://www.youtube.com/watch?v=zbL4LwmWAy0> November 27, 2017.

Associated General Contractors (2017). "Lean Construction Education Program," $<$ https://www.agc.org/learn/education-training/lean-construction-educationprogram>.Nov 26.

Bughin, J., Manyike, J., and Woetzl, J. (2017) Reinventing construction: a route to higher productivity, McKinsey Global Institute MGI@mckinsey.com, Feb, 2017.

Eastman, C., Teicholz, P., Sacks, R., and Liston, K. (2008). BIM Handbook: A Guide to Building Information Modeling for Owners, Managers, Designers, Engineers, and Contractors, John Wiley \&Sons, Hoboken, NJ.

ENR SmartMarket Report (2003). "Lean construction: Leveraging Collaboration and Advanced Practices to Increase Project Efficiency," McGraw-Hill Construction<https://www.leanconstruction.org/media/docs/Lean_Construction_SMR _2013.pdf>Nov 27.

ENR SmartMarket Report (2013). "Lean Construction:Leveraging Collaboration and Advanced Practices to Increase Project Efficiency. McGraw-Hill Construction.

Forbes, L. H. and Ahmed, S. M. (2011). Modern Construction: Lean Project Delivery and Integrated Practices, CRC Press / Taylor \& Francis Group, Boca Raton, 490 pp.

King, J. (2011). "Pull Planning Blocks Simulation.” DPR Construction, Oct 21, 2 pp.

Konchar, M., and Manshum, A. (2017). LCI 2017Update, Apresentation delivered to the $19^{\text {th }}$ LCI Congress, Anaheim, CA, October 19, 2017.

Koskela, L. (1992). Application of the New Production Philosophy to Construction, Technical Report \#72, CIFE, Dept. of Civil Engineering, Stanford University.

Koskela, L. (2000). An exploration towards a production theory and its application to construction. Espoo, VTT Building Technology, VTT Publications; 408, 296 pp.

Lean Construction Institute (LCI). (2017a). <https://www.leanconstruction.org/aboutus/what-is-lean-design-construction/history/> (November 26, 2017).

Lean Construction Institute (LCI). (2017b). Make-a-Card Simulation, Parade-of-Trades Simulation, and Silent Squares Simulation, <https://www.leanconstruction.org/learning/game-simulations/>Nov 26.

Lean Construction Journal (LCJ). (2017). <https://www.leanconstruction.org/aboutus/publications/lean-construction-journal/> (November 26, 2017).

Macomber, H. and Davey, C. (2017). The Pocket Sensei: Mastering Lean Leadership in 40 Weekly Exercises: Volume I, CreateSpace Publishing, 233 pp.

Superteams. (2016). The 5S Numbers Game<http://www.superteams.com/new-site/wpcontent/uploads/2016/04/SuperTeams5SGameHandout.pdf> November 26, 2017.

Teicholz, P. (September/October, 2001). U.S. construction labor productivity trends, 1970-1998, Journal of Construction Engineering and Management, 127(5), 427-429.

Tsao, C. C. Y., Draper, J., and Howell, G. A. (2014). "An overview, analysis, and facilitation tips for simulations that support and simulate pull planning," IGLC22Proceedings, Oslo, Norway.

Tommelein, I.D., Riley, D.R., and Howell, G.A. (1999). "Parade Game: Impact of Work Flow Variability on Trade Performance." JCEM, ASCE, 125(5), 304-310. 
Villego® Last Planner® Simulation. (2017). <https://www.villego.com/>Nov 26.

Visionary Products Inc. (2008). "Lean Zone Production Methodologies." <http://www.visionaryproducts.biz/index.cfm?action=view\&pdfid=232.>Feb 28.

Wujec, T. (2012). "Build a tower. Build a Team." (TED Talk) <https://www.ted.com/talks/tom_wujec_build_a_tower>, April 22, 2018. 